\title{
UTILIZAÇÃO DE FUNGOS EM FORRAGEIRAS E NA ALIMENTAÇÃO DE RUMINANTES - REVISÃO
}

\author{
MONÇÃO, Flávio Pinto "; \\ RIGUEIRA, João Paulo Sampaio ${ }^{2}$; \\ SALES, Eleuza Clarete Junqueira de ${ }^{2}$; \\ LEAL, Dijair Barbosa ${ }^{3}$; \\ SILVA, Janaína Tayna ${ }^{3}$; \\ LEITE, Gabriela Duarte Oliveira ${ }^{3}$; \\ CHAMONE, Julieta Maria de Alencar ${ }^{2}$.
}

Recebido: 04/11/2016

Aceito: 14/06/2018

${ }^{1}$ Professor colaborador do Programa de Pós-Graduação em Zootecnia/Unimontes; ${ }^{2}$ Professor do Departamento de Ciências Agrárias/Unimontes; ${ }^{3}$ Estudante do Curso de Zootecnia/Unimontes.

\section{RESUMO}

\begin{abstract}
A utilização de plantas forrageiras como fonte de nutrientes para ruminantes é sem dúvida a forma mais econômica e competitiva de produzir carne e leite de qualidade nos trópicos. Entretanto, em regiões de clima tropical, a produção de forragem não é constante ao longo do ano, sendo essencial conservar o excesso de forragem produzida em épocas estratégicas na forma de fenos, silagens e diferimentos dos pastos. Entretanto, a conservação de forragens de modo geral não mantém constante o valor nutricional do alimento, sendo essencial a adoção de técnicas eficientes e economicamente viáveis com o intuito de melhorar a qualidade nutricional da forragem conservada. Com base no exposto, objetivou-se por meio desta revisão elucidar a importância dos fungos sobre o valor nutricional de plantas forrageiras conservadas e reunir informações sobre sua utilização na alimentação animal. $\mathrm{O}$ uso de fungos como suplemento de forragens apresenta potencial no desempenho animal, principalmente pelo valor nutricional de alguns fungos como as leveduras.
\end{abstract}

Palavras-chave: Análise de alimentos. Conservação. Hifas. Valor nutricional. 


\section{INTRODUÇÃO}

Na maioria das regiões brasileiras, a pecuária de corte e leite apresenta papel fundamental no desenvolvimento socioeconômico, com ampla participação no produto interno bruto do agronegócio do país (31\%) (ABIEC, 2017). Entretanto, na maioria das regiões brasileiras, os sistemas produtivos de exploração animal apresentam baixos índices de produtividade, em função de vários fatores, principalmente pelo déficit na oferta de alimentos. Os animais estão sujeitos às carências nutricionais por causa do longo período de estiagem, baixo valor nutricional e reduzida capacidade de suporte dos pastos, limitando a oferta de alimentos ao mercado consumidor (SAMPAIO et al., 2017).

O menor valor nutritivo das plantas forrageiras, principalmente nos períodos de maior escassez de chuva, está relacionado com a lignificação da parede celular em função da idade fisiológica da planta, constituindo um dos fatores que acarreta reduzida degradabilidade ruminal, devido sua complexação com os carboidratos fibrosos (MONÇÃO et al., 2016b; VAN SOEST, 1994). A lignina apresenta resistência à degradação química, não sendo degradada pelas bactérias ruminais, formando complexas associações com a celulose (lignocelulose) e a hemicelulose (ligações do tipo éster), reduzindo a degradação da fração fibrosa no rúmen (VAN SOEST, 1994). Neste sentido, a inoculação de forragens com fungos lignocelulolíticos é uma premissa para melhorar a digestibilidade. Pesquisas como a de Schmidt et al. (2003b) demonstraram que o tratamento do substrato (forragem) sob influência da ação do fungo (Pleurotus ostreatus) pode melhorar o perfil de fermentação no rúmen.

Os frequentes incrementos dos custos da suplementação da dieta dos animais têm estimulado o interesse pelo aproveitamento de alimentos não convencionais na indústria de alimentação animal do Brasil (MONÇÃO et al., 2016a). Dentre os produtos que apresentam potencial de substituir os suplementos proteicos, por exemplo, e suprir os nutrientes deficientes nos pastos, destacam-se as algas, fungos filamentosos e, principalmente, leveduras obtidas a partir da fermentação da cevada e da cana-de-açúcar, considerados fonte de proteínas, além de apresentarem rápido crescimento e possibilidade de cultivo em vários tipos de substratos (SARTORI et al., 2017). 
A exploração desses microrganismos tornou-se evidente a partir da Segunda Guerra Mundial, época em que se tornaram escassos os alimentos ricos em proteínas e vitaminas. Com isso, os alemães produziram, em escala, leveduras e fungos, principalmente, do gênero Geotrichum candidum para serem usados na alimentação humana, conforme citaram Frazier e Westhoff, (1993).

Com base no exposto, objetivou-se por meio desta revisão elucidar a importância dos fungos sobre o valor nutricional de plantas forrageiras conservadas e sua utilização na alimentação animal.

\section{FUNGOS E ALIMENTAÇÃO ANIMAL}

\section{Ação dos fungos nos componentes da parede celular}

A conservação das plantas forrageiras tropicais ou resíduos agroindustriais, quando realizada de forma equivocada, pode resultar na conservação de um material que é caracterizado como de baixo valor nutritivo, por apresentar alto teor de componentes da parede celular e teor de proteína bruta, resultando em reduzida degradabilidade e digestibilidade da matéria seca. Segundo Van Soest (1994), a parede celular das plantas forrageiras é constituída, principalmente, por três compostos ligados entre si: a celulose, a hemicelulose e a lignina, sendo a última considerada o principal fator limitante à degradabilidade e digestibilidade das forrageiras.

Com a finalidade de melhorar a degradabilidade e digestibilidade dos nutrientes no rúmen, os tratamentos físicos, químicos ou biológicos da forragem são uma alternativa interessante, porque podem promover alterações na estrutura da parede celular (MORAIS et al., 2016). Assim, os tratamentos biológicos consistem na inoculação com microrganismos, fungos e bactérias, que atuam sobre o substrato, degradando preferencialmente os compostos fenólicos, como a lignina, sem promover perdas consideráveis de celulose e hemicelulose (SCHMIDT et al., 2003a).

Os tratamentos das forragens com fungos apresentam segurança em termos de preservação ambiental, devido a não utilizarem compostos químicos durante o processo, surgindo como alternativa alimentar na produção sustentável de ruminantes. No entanto, os resultados 
disponíveis na literatura sobre tratamentos de forragens por meio de fungos e seus efeitos sobre o valor nutricional destas são escassos e contraditórios (SCHMIDT et al., 2003b).

Para Karunanandaa et al. (1996), a espécie do fungo é um fator fundamental na melhora da qualidade do material, além da fração botânica estudada e da preparação prévia do substrato para degradação fúngica. Para Rajarathnam e Bano (1989), o tratamento inicial do substrato lignocelulósico tem grande influência na taxa de colonização pelo gênero de Pleurotus e, consequentemente, no aumento da solubilidade do substrato. Platt et al. (1981), cultivando Pleurotus sob palha de arroz afirmaram que 40 a $50 \%$ do conteúdo de lignina pode ser reduzida em um período de 35 a 45 dias, sendo que a degradação da lignina é maior durante o período inicial de colonização do substrato (corrida do micélio). Silveira et al. (2008), avaliando as características nutricionais de banana in natura sob ação de fungos Pleurotus, observaram degradação de $80,36 \%$ da lignina e aumento da digestibilidade da matéria seca em 187\%. Essa degradação da lignina deve-se a produção de uma série de enzimas lignocelulases por fungos deste gênero, que degradam facilmente a lignina e a celulose de plantas forrageiras e resíduos agroindustriais de baixo valor nutritivo (AGUIAR; FERRAZ, 2011).

Schmidt et al. (2003a) trataram feno de braquiária (Brachiaria decumbens) com fungo $P$. ostreatus durante 35 dias para melhorar a degradação da fração lignocelulósica, verificando que o fungo teve maior ação sobre a hemicelulose, promovendo maior degradação da mesma (32,70\%). Embora Rajarathnam e Bano (1989) e Adamovic et al. (1998) afirmem que os fungos da classe basidiomicetos provocam degradação preferencial da lignina.

Em suma, as forrageiras tropicais apresentam elevados teores de componentes da parede celular, principalmente em pastos manejados após atingirem maturidade fisiológica, acarretando menor aproveitamento ruminal dos nutrientes. Todavia, a inoculação com fungos Pleurotus incrementa a digestibilidade da parede celular.

\section{Leveduras}

As leveduras são fungos unicelulares eucariontes, ou seja, são organismos que apresentam um núcleo organizado devido à presença de carioteca, e pertencem ao Reino Fungi. Por serem organismos aclorofilados, não produzem o seu próprio alimento. As leveduras são 
organismos facultativos, podendo viver tanto na presença como na ausência de oxigênio, sendo sua reprodução rápida na presença de oxigênio (TORTORA et al. 2000). Ocorrem naturalmente dentro do rúmen (LUND, 1974). A limitada reprodução destes microrganismos dentro do rúmen sugere que as leveduras nele presentes sejam membros transitórios do fluido, continuamente introduzidos pela alimentação (VAN SOEST, 1994).

Para Maamouri et al. (2014) a levedura, conhecida cientificamente como Saccharomyces cerevisiae, é o microrganismo mais utilizado na indústria de alimentos fermentescíveis. Estas são denominadas de leveduras primárias, quando resultantes dos processos exclusivamente destinados a produção, que é o caso de fermento biológico, e as leveduras secundárias são aquelas obtidas como coprodutos de outras indústrias fermentativas (ARAÚJO et al., 2009).

Os procedimentos para a produção da levedura (S. cerevisiae) de cana-de-açúcar é totalmente natural, obtido a partir da fermentação da cana-de-açúcar, podendo ter significativa importância na alimentação animal (ARAÚJO et al., 2009). A cana-de-açúcar é um alimento volumoso, rico em carboidratos fibrosos e não fibrosos, como a sacarose. Como as leveduras são seres heterotróficos, utilizam os carboidratos dos alimentos para se alimentar. Com isso, a fermentação ocorre em função da levedura executar o metabolismo fermentativo dos carboidratos polissacarídeos presente na cana-de-açúcar ou na cevada, por exemplo, e liberá-la na forma de monossacarídeos (ANGELIS, 1986).

A composição química e o valor nutricional da levedura variam em função de uma série de fatores, dentre esses, destacam-se o substrato utilizado, o tratamento da massa fluida, as concentrações de sais e o meio de cultura de onde provém a levedura. As leveduras apresentam em sua composição de 8,72 a 10,02\% de umidade, $28,70 \%$ de proteína bruta, podendo chegar a 50,19\%, 0,91 a 1,03\% de extrato etéreo, 4,77\% de matéria mineral, 2,39\% de fibra em detergente neutro e 32,86\% de carboidratos totais (CABALLERO-CÓRDOBA et al., 1997).

Além de apresentar altos teores de proteína bruta (acima de 20\% da matéria seca), a levedura apresenta como característica um bom balanceamento de aminoácidos, onde os níveis, principalmente de metionina e lisina, sobressaem em relação às demais fontes proteicas (ARAÚJO et al., 2009). Ainda, são fonte de vitaminas do complexo B 
(principalmente tiamina, riboflavina, niacina e ácido pantatênico), contendo mais de 10 vitaminas solúveis na água (NISBET; MARTIN, 1991). As leveduras favorecem a produção de vitamina D no organismo, por apresentarem quantidade razoável de ergosterol. Nos triglicerídeos predominam os ácidos, portanto, semelhante à composição dos óleos vegetais (ANGELIS, 1986).

Callaway e Martin (1997) afirmaram que a produção microbiana de vitamina do complexo B e ácidos orgânicos seria satisfatória para atender a exigência por estes nutrientes para o animal e para a microbiota ruminal. Entretanto, esta síntese pode não ser constante entre as diferentes dietas. Desta forma, o suprimento de leveduras resultaria em uma maior concentração desses fatores solúveis, estimulando a síntese microbiana.

\section{Fungos na alimentação animal}

São poucos os trabalhos disponíveis na literatura sobre a utilização de fungos em forragens com fins à alimentação animal. Entretanto, foi relatada por alguns pesquisadores a caracterização e a importância do uso de fungos como fonte proteica para ruminantes (THRUNE et al., 2009; TITI et al., 2008) e aditivo para forragens (SCHMIDT et al., 2003a).

Alguns trabalhos (THRUNE et al., 2009; TITI et al., 2008) têm analisado a importância de alguns dos componentes do Reino Fungi, como as leveduras (S. cerevisiae) na alimentação animal e constataram que o uso de leveduras vivas tem demonstrado potencial em diminuir os riscos de acidose ruminal, melhorar a digestibilidade em forragens, aumentar o ganho de peso, a eficiência alimentar e a produção de leite (CAMPANILE et al., 2008). Esse aditivo estimula o crescimento, utilização de lactato e a degradação da fibra (TANG et al., 2008) por microrganismos ruminais.

A produção de proteína celular para consumo animal é considerada como uma fonte alternativa de alimentos, a qual elimina as restrições sazonais e as variações climáticas que existem em muitas regiões, uma vez que a seleção de microrganismos pode ser baseada no valor nutricional e no conteúdo proteico (ARAÚJO et al., 2009). Quando produzida em larga escala, a síntese de proteína celular pode constituir em uma das soluções ao problema de deficiência alimentar existente, principalmente em regiões de menor índice pluviométrico, onde os animais passam por uma restrição alimentar quantitativa e qualitativa. Portanto, a 
produção de células microbianas para nutrição animal vem sendo explorada como alternativa para o aumento da quantidade e qualidade da alimentação (ARAÚJO et al., 2009).

Newbold et al. (1996) argumentaram que a modificação do ambiente ruminal, iniciada a partir do uso de compostos antimicrobianos, como ionóforos, obteve sucesso em relação à melhora na eficiência produtiva dos animais ruminantes e que leveduras passaram a ser utilizadas na alimentação animal com o mesmo propósito, principalmente em forragens.

Neste sentido, Franco et al. (2008), avaliaram os parâmetros ruminais e o desaparecimento da matéria seca e fração fibrosa da forragem em bovinos recebendo levedura e enzimas fibrolíticas na dieta e constataram que a ação das leveduras sobre o $\mathrm{pH}$ ruminal ficou prejudicada, possivelmente pelo reduzido teor de açúcar e amido fermentável da forragem (Cynodon dactylon cv. Coast cross), não havendo contribuição para o aumento de lactato com consequente diminuição do $\mathrm{pH}$. Além disso, o possível efeito da levedura, que contribui para uma resistência à queda no pH ruminal, estaria relacionado ao estímulo a protozoários que engolfam muito rapidamente os grânulos de amido (entodinomorfos) e liberam, como produtos finais, ácidos graxos voláteis, antes do lactato (FONTY; CHAUCHEYRAS-DURAND, 2006).

Para Franco et al. (2008) alguns estudos in vitro destacaram o efeito da utilização de leveduras sobre o crescimento e a atividade dos microrganismos fibrolíticos no rúmen. As leveduras atuariam no incremento da colonização da parede celular das forragens pelos fungos, por meio do suprimento de tiamina ou da retirada de oxigênio do meio ruminal, favorecendo o ambiente para a maioria dos microrganismos ruminais que são altamente sensíveis ao oxigênio (FONTY; CHAUCHEYRAS-DURAND, 2006).

$\mathrm{Na}$ avaliação das dietas compostas de silagem de cevada e cevada grão, Beauchemin et al. (1999) observaram incremento de $58,80 \%$ para $61,70 \%$ sobre a digestibilidade total da fibra em detergente neutro com a adição de leveduras, mas não notaram efeito sobre o consumo e a degradação ruminal dos nutrientes. 
Tang et al. (2008) avaliaram a adição de leveduras e enzimas fibrolíticas sobre as palhas de cereais (arroz e trigo) e constataram que estas adições podem melhorar a fermentação de volumosos de baixa qualidade.

Gomes et al. (2010) compararam os efeitos das leveduras vivas e monensina em dietas de alto concentrado para bovinos e observaram que a monensina sódica atuou melhor sobre os parâmetros da degradabilidade ruminal da matéria seca. Para os autores, existem inconsistências das propriedades da levedura sobre o ambiente ruminal. A literatura existente a respeito do uso de leveduras vivas em dietas a base de forragem para ruminantes tem se mostrado bastante variável (GOMES et al., 2010). Alguns trabalhos permitem inferir que os efeitos da levedura sobre a fermentação ruminal podem ser variáveis em função da cepa utilizada e da concentração do aditivo no alimento (SULLIVAN; MARTIN, 1999).

Outros trabalhos, como o de Moya et al. (2009), permitiram evidenciar que não houve qualquer benefício da adição de leveduras, nem mesmo em situações de desafio ao ambiente ruminal.

Por outro lado, Wohlt et al. (1991) avaliaram a suplementação de $10 \mathrm{~g}$ de leveduras/vaca/dia em um experimento que teve início trinta dias antes da data prevista para o parto e se estendeu por dezoito semanas pós-parto. A dieta utilizada no ensaio consistiu de $50 \%$ de silagem de milho e $50 \%$ de concentrados. Houve resposta da suplementação de leveduras no consumo de matéria seca (MS) da dieta $(14,9 \mathrm{~kg} / \mathrm{vaca} / \mathrm{dia})$ em relação ao tratamentocontrole (13,8 kg/vaca/dia) nas seis primeiras semanas de lactação. Carvalho et al. (2009), avaliando o efeito da levedura associada com bicarbonato em dietas a base silagem de sorgo observaram aumento no consumo de matéria seca, quando associaram $2,20 \%$ de bicarbonato na matéria seca com $20 \mathrm{~g}$ de leveduras/vaca/dia. Observou-se que as vacas que receberam dietas com leveduras associadas com bicarbonato consumiram maior quantidade de matéria seca e fibra em detergente neutro, apresentando maior digesta ruminal. Entretanto, as dietas que continham leveduras isoladas apresentaram maior degradação ruminal da matéria seca e da fração fibrosa em relação ao controle e não diferiram das dietas tratadas com apenas bicarbonato e a associação entre bicarbonato e leveduras. 
Segundo Russell e Chow (1993), a elevação da concentração de sódio no rúmen resulta no aumento da pressão osmótica e faz com que o animal consuma mais água, até o ponto de equilíbrio desta pressão. A maior ingestão de água, por sua vez, aumenta o teor de fração líquida da digesta ruminal, fazendo com que a taxa de passagem se torne mais rápida e, consequentemente, aumente o consumo de matéria seca da dieta. Em relação às leveduras, pode ter ocorrido efeito da atividade respiratória de $S$. cerevisiae, diminuindo a concentração de $\mathrm{O}_{2}$ no rúmen e aumentando a adesão das bactérias celulolíticas à celulose (NEWBOLD et al., 1996), o que resultou em melhoria da degradabilidade desse carboidrato fibroso e, portanto, no aumento do consumo de matéria seca. Estes dois modos de ação distintos (tanto do bicarbonato quanto das leveduras) apresentaram efeito somatório quando associados.

Comportamento semelhante também foi observado por Schmidt et al. (2003a) que avaliaram feno de Brachiaria decumbens tratado com fungo da espécie $P$. ostreatus e observaram incremento de $39,62 \%$ nos teores de proteína bruta, redução de $15 \%$ no teor de fibra em detergente neutro após 35 dias de incubação do feno. Os autores constataram que o feno, quando tratado com fungo Pleurotus, adotando o manejo de compostagem do material inteiro e picado, apresentou maior teor de proteína bruta e lignina em relação ao controle e aos manejos na forma de hidratação do feno com água fria e quente. Entretanto, houve perda de matéria seca, decorrente do crescimento e metabolismo do fungo, que apresentaram grande variação entre parcelas. Berger et al. (1994) citam trabalhos nos quais a fermentação sólida de resíduos lignocelulósicos acarretou perdas de matéria seca de 17 a $42 \%$. Segundo estes autores, estas perdas, bem como o longo tempo necessário para o tratamento, são as principais desvantagens do uso de fungos da podridão branca no tratamento biológico. Entretanto, quando o feno tratado, independente do manejo, foi incubado na forma de silo e compactado para retirada de ar durante 35 dias, houve redução linear de 0,$35 ; 0,15 ; 0,28$ e $0,23 \%$ nos teores de fibra em detergente neutro, celulose, hemicelulose, hemicelulose associada com fibra em detergente neutro, respectivamente, para cada dia incrementado na incubação. Por outro lado, houve incremento nos teores de proteína bruta $(0,05 \%)$ e lignina associada com fibra em detergente neutro $(0,11 \%)$ em relação ao controle. 
O aumento nos teores de proteína bruta com o decorrer da incubação deve ser atribuído à perda de carboidratos característica dos crescimentos fúngicos. O teor médio de proteína bruta foi elevado em 39\% entre o início e o final da incubação. Nicolini et al. (1993) observaram aumentos de 18,70\% no teor de proteína bruta após 70 dias de incubação com P. ostreatus na palha de trigo. Na pesquisa de Bisaria et al. (1997), o aumento no teor de proteína bruta, após 20 dias de incubação, foi de 141,90\%, usando o mesmo fungo e volumoso, em condições de laboratório.

Schmidt et al. (2003a) concluíram que a incubação do feno de braquiária inoculado com $P$. ostreatus propicia degradação da fração fibrosa e aumento no teor de lignina. Conforme os autores, as perdas de matéria seca decorrentes do metabolismo fúngico apresentaram-se muito variáveis, sem efeito detectável de tratamento. $O$ aumento na concentração da lignina na parede celular pode ser explicado por esta ação preferencial do fungo na hemicelulose.

Outro resultado interessante usando fungos da espécie $P$. sapidus no tratamento de silagem de cana-de-açúcar foi constatada por Peláez Acero et al. (2008), que verificaram aumentos de 13,60; 40,24 e 3\% respectivamente sobre os teores de matéria seca, proteína bruta e matéria orgânica. Os autores também observaram que a adição de 10 a $20 \%$ de fungos $P$. sapidus sobre o teor de matéria seca da cana-de-açúcar in natura e ensilada aumenta a digestibilidade e melhora os parâmetros fermentativos elevando o valor nutricional de produto de baixa qualidade.

\section{CONCLUSÃO}

O uso de fungos como suplemento de forragens apresenta potencial no desempenho animal, principalmente pelo valor nutricional de alguns fungos como as leveduras. Entretanto, investigações futuras devem avaliar esses aditivos em situações mais desafiadoras ao ambiente do rúmen. 


\section{USE OF FUNGI IN FORAGE AND IN THE RUMINANT FEED - REVIEW}

\section{ABSTRACT}

\section{$\mathrm{T}$}

he use of forage plants as a source of nutrients for ruminants is undoubtedly the most economical and competitive way to produce meat and milk of quality in the tropics. However, in tropical regions, forage production is not constant throughout the year, being essential to keep the excess forage produced at strategic times in the form of hay, silage and deferrals of pastures. However, the conservation of forage generally does not maintain constant the nutritional value of the food, the adoption of efficient and economically viable techniques in order to improve the nutritional quality of conserved forage is essential. Based on the informatins above, this review aimed to elucidate the importance of fungi in the nutritional value of conserved forage plants gathering information about their use in animal feed. The use of fungi as a forage supplement has potential in animal performance, mainly due to the nutritional value of some fungi such as yeasts.

Keywords: Food analysis. Conservation. Hyphae. Nutritional value.

\section{UTILIZACIÓN DE HONGOS EN FORRAJERAS Y EN LA ALIMENTACIÓN DE RUMINANTES - REVISIÓN}

\section{RESUMEN}

a utilización de plantas forrajeras como fuente de nutrientes para rumiantes es sin duda la forma más económica y competitiva de producir carne y leche de calidad en los trópicos. Sin embargo, en regiones de clima tropical, la producción de forraje no es constante a lo largo del año, siendo esencial conservar el exceso de forraje producido en épocas estratégicas en forma de heno, ensilajes y reservas de pastura. Sin embargo, la conservación de forrajes en general no mantiene constante el valor nutricional del alimento, siendo esencial la adopción de técnicas eficientes y económicamente viables con el fin de mejorar la calidad nutricional del forraje conservado. Con base en lo expuesto, se objetivó por medio de esta revisión dilucidar la importancia de los hongos sobre el valor nutricional de plantas forrajeras conservadas y reunir informaciones sobre su utilización en la alimentación animal. El uso de hongos como suplemento de forrajes presenta potencial en el desempeño animal, principalmente por el valor nutricional de algunos hongos como las levaduras.

Palabras clave: Análisis de alimentos. Conservación. Hifas. Valor nutricional. 


\section{REFERÊNCIAS}

ABIEC - ASSOCIAÇÃO BRASILEIRA DAS INDÚSTRIAS EXPORTADORAS DE CARNE - Perfil da Pecuária no Brasil - Relatório anual - 2017. Disponível em: <http://gtps.org.br/wpcontent/uploads/2017/08/Sumario_2017_screen.pdf>.

ADAMOVIC, M.; GRUBIC, G.; MILENKOVIC, I.; et al. The biodegradation of wheat straw by Pleurotus ostreatus mushrooms and its use in cattle feeding. Animal Feed Science Technology, v. 71, n.3-4, p. 357-362, 1998.

AGUIAR, A.; FERRAZ, A. Mecanismos envolvidos na biodegradação de materiais lignocelulósicos e aplicações tecnológicas correlatas. Química Nova, v. 34, n. 10, p. 17291738, 2011.

ANGELIS, D. F. Emprego de leveduras em culturas puras e mistas objetivando o aproveitamento da vinhaça. Rio de janeiro: Brasil Açucareiro, 1986. 406p.

ARAÚJO, L. F.; DIAS, M. V. C.; BRITO, E. A.; et al. Enriquecimento proteico de alimentos por levedura em fermentação semissólida: alternativa na alimentação animal. Tecnologia e Ciências Agropecuárias, v. 3, n. 3, p. 47-53, 2009.

BEAUCHEMIN, K. A.; YANG, W. Z.; RODE, L. M. Effects of grain souce and enzyme additive on site and extend of nutrient digestion in dairy cows. Journal of Dairy Science, v. 82, n. 2, p. 378-390, 1999.

BERGER, L. L.; FAHEY, G. C.; BOURQUIN, L. D.; et al. Modification of forage after harvest. In: BARNES, R. F.; COLLINS, M.; EMIL, B.; et al. Forage quality, evaluation, and utilization. Madison: American Society of Agronomy, Crop Science Society, Soil Science Society, 1994. Cap. 23, p. 922-966.

BISARIA, R.; MADAN, M.; VASUDEVAN, P. Utilization of agro-residues as animal feed through bioconversion. Bioresource Technology, v. 59, n. 1, p. 5-8, 1997.

CABALLERO-CÓRDOBA, G. M.; PACHECO, M. T. B.; SGARBIERI, V. C. Composição química da biomassa de levedura integral (Saccharomyces sp.) e determinação do valor nutritivo da proteína em células íntegras ou rompidas mecanicamente. Ciência e Tecnologia de Alimentos, v. 17, n. 2, p. 102-106, 1997.

CALLAWAY, E. S.; MARTIN, S. A. Effects of Saccharomyces cerevisiae culture on ruminal bacteria that utilize lactate and digest cellulose. Journal of Dairy Science, v. 80, n. 9, p. 20352044, 1997.

CAMPANILE, G.; ZICARELLI, F.; VECCHIO, D.; et al. Effects of Saccharomyces cerevisiae on in vivo organic matter digestibility and milk yield in buffalo cows. Livestock Science, v. 114, n. 2-3, p. 358-361, 2008. 
CARVALHO, E. R.; SANTOS, S. C.; CAETANO, T. F.; et al. Bicarbonato de sódio e leveduras como aditivos de dietas para vacas leiteiras mestiças. Ciência Animal Brasileira, v. 10, n. 2, p. 511-526, 2009.

FONTY, G.; CHAUCHEYRAS-DURAND, F. Effects and modes of action of live yeasts in the rumen. Biologia, v. 61, n. 6, p. 741-750, 2006.

FRANCO, G. L.; FERREIRA, R. F.; ROCHA, M. T.; et al. Parâmetros ruminais e desaparecimento da matéria seca e fibra em detergente neutro da forragem em bovinos que recebendo levedura e enzimas fibrolíticas na dieta. Revista Brasileira de Saúde e Produção Animal, v. 9, n. 3, p. 488-496, 2008.

FRAZIER, W. C.; WESTHOFF, D. C. Microbiologia de los alimentos. 4. ed. Zaragoza: Acribia, 1993. 618p.

GOMES, R. C.; ANTUNES, M. T.; NOGUEIRA FILHO, J. C. M.; et al. Leveduras vivas e monensina em dietas de alto concentrado para bovinos: parâmetros ruminais e degradabilidade "in situ". Revista Brasileira de Saúde e Produção Animal, v. 11, n. 1, p 202216, 2010.

KARUNANANDAA, K.; VARGA, G. A. Colonization of crop residues by white-rot fungi: cell wall monosaccharides, phenolic acids, ruminal fermentation characteristics and digestibility of cell wall fiber components in vitro. Animal Feed Science Technology, v. 63, p. 273-288, 1996.

LUND, A. Yeasts and Moulds in the Bovine Rumen. Journal of General Microbiology, v. 81, n. 2, p. 453-462, 1974.

MAAMOURI, O.; SELMI, H.; M'HAMDI, N. Effects of Yeast (Saccharomyces cerevisiae) Feed Supplement on Milk Production and its Composition in Tunisian Holstein Friesian Cows.

Scientia agriculturae bohemica, v. 45, n. 3, p. 170-174, 2014.

MONÇÃO, F. P.; OLIVEIRA, E. R.; GABRIEL, A. M. A.; et al. Nutritional parameters of leaf blade from different tropical forages. Scientia Agraria Paranaensis, v. 15, n. 2, p. 185-193, 2016a.

MONÇÃO, F. P.; REIS, S. T.; RIGUEIRA, J. P. S.; et al. Ruminal degradation of dry matter and neutral detergent fiber of banana peel treated with limestone. Semina: Ciências Agrárias, v. 37, n. 1 , p. 345-356, 2016b.

MORAIS, L. F.; NEPOMUCENO, D. D.; ALMEIDA, J. C. C. Tratamentos de volumosos de baixo valor nutritivo para ruminantes - uma revisão. Acta Tecnológica, v. 11, n. 1, p. 1-16, 2016.

MOYA, D.; CALSAMIGLIA, S.; FERRET, A.; et al. Effects of dietary changes and yeast culture (Saccharomyces cerevisiae) on rumen microbial fermentation of Holstein heifers. Journal of Animal Science, v. 87, n. 9, p. 2008-1446, 2009. 
NEWBOLD, C. J.; WALLACE, R. J.; MCINTOSH, F. M. Mode of action of the yeast Saccharomyces cerevisiaeas a feed additive for ruminants. British Journal of Nutrition, v. 76, n. 2, p. 249-261, 1996.

NICOLINI, L.; VOLPE, C.; PEZZOTTI, A. Changes in in vitro digestibility of orange peels and distillery grape stalks after solid-state fermentation by higher fungi. Bioresource Technology, v. 45, p. 17-20, 1993.

NISBET, D. J.; MARTIN, S. A. Effect of a Saccharomyces cerevisia e culture on lactate utilization by the ruminal bacterium Selenomonas ruminantium. Journal of Animal Science, v. 69, n. 1, p. 4628-4633, 1991.

PELÁEZ ACERO, A.; MAYO, M. M; ROMERO, L. A. M.; et al. Ventajas de la fermentación sólida com pleurotus sapidus em ensilajes de caña de azúcar. Archuivos de Zootecnia, v. 57, n. 217, p. 25-33, 2008.

PLATT, M. W.; CHET, I.; HENIS, Y. Lignocellulose degradation during growth of the mushroom Pleurotus sp. Florida on cotton straw. European Journal of Applied Microbiology and Biotechnology, v. 13, p. 194-195, 1981.

RAJARATHNAM, S.; BANO, Z. Pleurotus mushrooms. Part III. Biotransformations of natural lignocellulosic wastes: commercial applications and implications. CRC Critical Reviews in Food Science and Nutrition, v. 28, n. 1, p. 31-113, 1989.

RUSSELL, J. B.; CHOW, J. M. Another theory for the action of ruminal buffer salts: decreased starch fermentation and propionate production. Journal of Dairy Science, v. 76, n. 3, p. 826830, 1993.

SAMPAIO, R. L.; RESENDE, F. D.; REIS, R. A.; OLIVEIRA, I. M.; CUSTÓDIO, L.; FERNANDES, R. M.; PAZDIORA, R. D.; SIQUEIRA, G. R. The nutritional interrelationship between the growing and finishing phases in crossbred cattle raised in a tropical system. Tropical Animal Health and Production, v. 49, n. 5, p. 1015-1024, 2017.

SARTORI, E. D.; CANOZZI, M. E. A.; ZAGO, D.; et al. The Effect of Live Yeast Supplementation on Beef Cattle Performance: A Systematic Review and Meta-Analysis. Journal of Agricultural Science, v. 9, n. 4, p. 1-17, 2017.

SCHMIDT, P.; WECHSLER, F. S.; NASCIMENTO, J. S.; et al. Tratamento do feno de braquiária pelo fungo Pleurotus ostreatus. Revista Brasileira de Zootecnia, v. 32, n. 6, p. 1866-1871, 2003a.

SCHMIDT, P.; WECHSLER, F. S.; NASCIMENTO, J. S.; et al. Valor nutritivo do feno de braquiária amonizado com ureia ou inoculado com Pleurotus ostreatus. Revista Brasileira de Zootecnia, v. 32, n. 6, p. 2040-2049, 2003b. 
SILVEIRA, M. L. L.; FURLAN, M. A.; NINOW, J. L. Development of an alternative technology for the oyster mushroom production using liquid inoculum. Food Science and Technology, v. 28, n. 4, p. 858-862, 2008.

SULLIVAN, H. M.; MARTIN, S. A. Effects of a Saccharomyces cerevisiae culture in vitro mixed ruminal microorganisms fermentation. Journal of Dairy Science, v. 82, n. 2, p. 2011-2016, 1999.

TANG, S. X.; TAYO, G. O.; TAN, Z. L.; et al. Effects of yeast culture and fibrolytic enzyme supplementation on in vitro fermentation characteristics of low-quality cereal straws. Journal of Animal Science, v. 86, n. 5, p. 1164-1172, 2008.

THRUNE, M.; BACH, A.; RUIZ-MORENO, M.; et al. Effects of Saccharomyces cerevisiae on ruminal $\mathrm{pH}$ and microbial fermentation in dairy cows: Yeast supplementation on rumen fermentation. Livestock Science, v. 124, n. 1-3, p. 261-265, 2009.

TITI, H. H.; DMOUR, R. O.; ABDULLAH, A. Y. Growth performance and carcass characteristics of Awassi lambs and Shami goat kids fed yeast culture in their finishing diet. Animal Feed Science and Technology, v. 142, n. 1-2, p. 33-43, 2008.

TORTORA, G. J.; FUNKE, B. R.; CASE, C. L. Microbiologia. 6. ed. Porto Alegre: Artmed, 2000, $827 p$.

VAN SOEST, P. J. Nutrition Ecology of the ruminant. 2. ed. Ithaca: Cornell Univ. Press, 1994. $476 p$.

WOHLT, J. E.; FINKELSTEIN, A. D.; CHUNG, C. H. Yeast culture to improve intake, nutrient digestibility and performance by dairy cattle during early lactation. Journal of Dairy Science, v. 74, n. 4, p. 1395-1400, 1991. 